Chapter 8

\title{
Chromatin Remodelling During Host-Bacterial Pathogen Interaction
}

\author{
Yong Zhong Xu, Cynthia Kanagaratham and \\ Danuta Radzioch
}

Additional information is available at the end of the chapter

http://dx.doi.org/10.5772/55977

\section{Introduction}

Eukaryotic DNA is tightly packaged into nucleosome repeats, which form the basic unit of cellular chromatin. The nucleosome consists of an octamer core wrapped with a segment of 146 base pairs of double stranded DNA. Each octamer core is composed of two molecules of each core histone proteins H2A, H2B, H3 and H4 (Figure 1). A fifth histone protein, linker $\mathrm{H} 1$, binds to the nucleosomal core particle and assists in further compaction of the chromatin into higher-order structure(Lusser and Kadonaga, 2003;Roberts and Orkin, 2004). This compaction of genomic DNA into chromatin restricts access of a variety of DNA regulatory proteins to the DNA strand, which are involved in the processes of transcription, replication, DNA repair and recombination machinery. To overcome these barriers, eukaryotic cells possess a number of multi-protein complexes which can alter the chromatin structure and make DNA more accessible. These complexes can be divided into two groups, histone-modifying enzymes and ATP-dependent chromatin remodelling complexes. The histone-modifying enzymes post-translationally modify the N-terminal tails of histone proteins through acetylation, phosphorylation, ubiquitination, ADP-ribosylation and methylation. On the other hand, ATP-dependent chromatin remodelling complexes use the energy of ATP hydrolysis to disrupt the contact between DNA and histones, move nucleosomes along DNA, and remove or exchange nucleosomes(Kallin and Zhang, 2004;:Lusser and Kadonaga, 2003;Roberts and Orkin, 2004). The importance of chromatin structure and its functional role in genome regulation and development is becoming increasingly evident, especially in diseases such as cancer. 
A

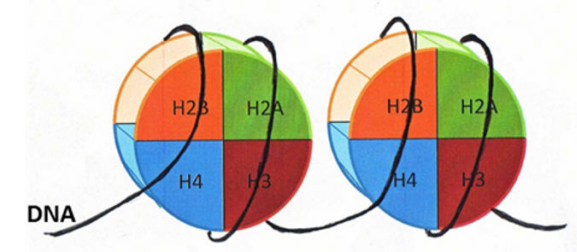

B

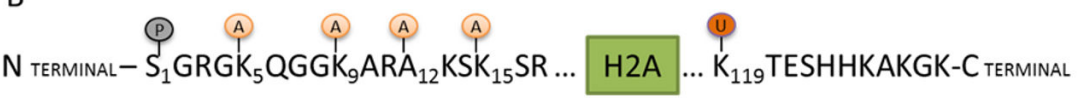

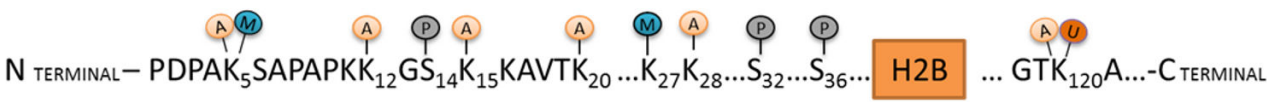

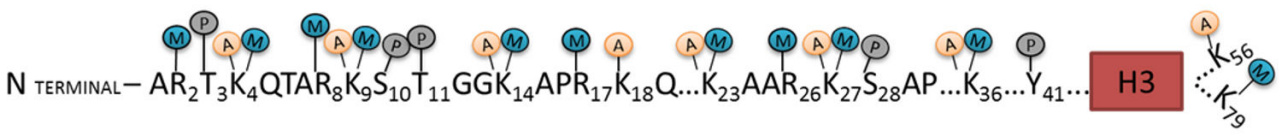

$\mathrm{N}$ terminal- $\mathrm{S}_{1} \mathrm{GR}_{3} \mathrm{GK}_{5} \mathrm{GGK}_{8} \mathrm{GLGK}_{12} \mathrm{GGAK}_{16} \mathrm{RH}_{18} \mathrm{RK}_{20} \mathrm{~V} \ldots \mathrm{H}_{4} \ldots-\mathrm{C}_{\text {teRminal }}$

Figure 1. Schematic representation of a nucleosome (A) and major histone modifications (B). Modifications on histones are described in text. The major modifications shown include acetylation (A), methylation (M), phosphorylation $(\mathrm{P})$ and ubiquitination $(\mathrm{U})$. Histone modifications mainly occur on the N-terminal tails of histones but also on the C-terminal tails and globular domains, for example, ubiquitination of the C-terminal tails of $\mathrm{H} 2 \mathrm{~A}$ and $\mathrm{H} 2 \mathrm{~B}$ and acetylation and methylation of the globular domain of $\mathrm{H3}$ at $\mathrm{K} 56$ and $\mathrm{K} 79$, respectively.

Intracellular pathogens, through a long-standing coexistence with host cells, have evolved mechanisms that provide pathogens with the amazing capacity to adapt and survive in the variable and often hostile environments of their hosts (Galan and Cossart, 2005). The concept of chromatin modification as a mechanism by which pathogens affect host immune responses to facilitate infection has emerged in recent years. For example, listeriolysin O (LLO), secreted by Listeria monocytogenes, induces a dramatic dephosphorylation of histone $\mathrm{H} 3$ at serine 10 and deacetylation of histone $\mathrm{H} 4$, and these modifications are associated with changes in host gene expression during early stages of infection (Hamon et al., 2007). Arbibe and colleagues also indicate that Shigella flexneri effector OspF dephosphorylates ERK and p38 mitogen-activated protein kinase (MAPK) in the nucleus; this subsequently prevents histone $\mathrm{H} 3$ phosphorylation at Ser10 at the promoters of a specific subset of genes, which blocks the activation of nuclear factor $-\kappa B(N F-\kappa B)$ - responsive genes leading to a compromised inflammation in the infected tissue(Arbibe et al., 2007). These results suggest a strategy developed by microbial pathogens 
to manipulate the host cellular function through histone modification and subversion of host innate immune responses for their survival or to infect the host.

Histone acetylation/deacetylation is a key epigenetic regulator of chromatin structure and gene expression, in combination with other posttranslational modifications. These patterns of histone modification are maintained by histone modifying enzymes such as histone acetyltransferases (HATs) and histone deacetylases (HDACs). While HATs acetylate histones, conferring an "open" chromatin structure that allows transcriptional activation, HDACs have the opposite effect resulting in transcriptional repression by closing chromatin structure. Global HDAC-mediated transcriptional changes can have a concomitant effect on cell function - an epigenetic mechanism often exploited by viruses to promote infection (Punga and Akusjarvi, 2000;Radkov et al., 1999; Valls et al., 2007). Recent reports also show that intracellular bacteria manipulate host cell epigenetics to facilitate infection (Arbibe et al., 2007;Hamon et al., 2007; Hamon and Cossart, 2008). Disruption of HDAC activity with inhibitors or by siRNA affects gene expression profilling in different cell types (Glaser et al., 2003a;Glaser et al., 2003b;Lee et al., 2004;Zupkovitz et al., 2006). The potential of HDAC inhibitors in treatment of infection has being studied.

In this chapter, the chromatin modifications in host cells induced by bacterial pathogens and their effects on host gene expression and infection will be reviewed. Furthermore, the potential role of HDAC inhibitors, as a therapeutic immunomodulator, in treatment of infections will also be discussed.

\section{Chromatin structure in transcription regulation}

The packaging of DNA into chromatin does not only simply facilitate the compaction of eukaryotic DNA genomes into the cell nucleus but also plays a profound and ubiquitous roles in almost all DNA-related cellular processes such as DNA replication, repair, recombination and transcription (Clapier and Cairns, 2009; Li et al., 2007a). Chromatin structure is not a simple static unit. It possesses dynamic properties that are orchestrated by ATP-dependent chromatin-remodeling complexes and histone-modifying enzymes. In conjunction with other coregulators, these chromatin remodelers modify histone-DNA interaction and regulate transcription at specific genomic loci.

\subsection{Histone modifications and transcription}

Histone sequences are highly conserved. A core histone protein typically consists of an unstructured N-terminal tail, a globular core including a central histone-fold domain, and a conformationally mobile C-terminal tail (Garcia et al., 2007b;Mersfelder and Parthun, 2006). Both N-terminal tails and globular domains are subject to a variety of posttranslational modifications (Kouzarides T, Cell, 2007, 128:693-705) (Figure 1). At least fourteen different types of posttranslational (or covalent) modifications involving more than 60 different residues on histones have been reported to date including acetylation, methylation, phosphorylation, ubiquitination, poly-ADP ribosylation, sumoylation, butyrylation, formylation, deimination, 
citrullination, isomerisation, O-GlcNAcylation, crotonylation and hydroxylation (Martin and Zhang, 2007;Ruthenburg et al., 2007;Sakabe et al., 2010;Tan et al., 2011). The majority of known histone modifications are located within the N-terminal tails of core histones. These modifications play an important role in the control of chromatin dynamics and its availability for transcription (Kouzarides, 2007). It has been suggested that all these modifications are combinatorial and interdependent and therefore may constitute a "histone code" (Jenuwein and Allis, 2001;Strahl and Allis, 2000). According to this hypothesis, the "histone code" is read by effector proteins (readers) which recognize and bind to modifications via specific domains and result in distinct and consistent cellular processes, such as replication, transcription, DNA repair and chromosome condensation (Kouzarides, 2007;Shi and Whetstine, 2007). Specific histone modifications are essential for partitioning the genome into functional domains, such as transcriptionally silent heterochromatin and transcriptionally active euchromatin (Martin and Zhang, 2005).

There are two major mechanisms underlying the function of histone modifications (Kouzarides, 2007;Ruthenburg et al., 2007). The first is the modulation of chromatin structure either by altering DNA-nucleosome interaction or by altering nucleosome-nucleosome interactions via changing the histone charges or by addition of physical entities. For example, histone acetylation, a modification associated with transcriptional activation, has been proposed to unfold chromatin structure via neutralization of the basic charges of lysines (Kouzarides, 2007). Indeed, in vitro studies using recombinant nucleosomal arrays have demonstrated that acetylation of H4K16 restricts the formation of a 30-nanometer fiber and the generation of higher-order structures (Shogren-Knaak et al., 2006;Shogren-Knaak and Peterson, 2006). Secondly, histone modifications provide docking sites for the recruitment of specific binding proteins, which recognize and interact with modified histones via specialized domains such as bromo-, chromo- and PHD (plant homeodomain) domains, thereby influence chromatin dynamics and function (Wysocka et al., 2005;Wysocka et al., 2006b;Zeng and Zhou, 2002). A number of proteins have been identified that are recruited to specific modifications. For example, methylation of H3K4, H3K9 and H3K27 can be recognized by inhibitor of growth (ING) proteins, heterochromatin protein 1 (HP1) and polycomb proteins, respectively. It has been shown that histone modification binding proteins can tether, directly or indirectly, an enzyme to chromatin. The activity of this recruited enzyme can be regulated (Pena et al., 2006;Shi et al., 2006; Wysocka et al., 2006b). BPTF, a component of the NURF chromatin remodelling complex, binds to H3K4me3 via a PHD domain and tethers the SNF2L ATPase to H0XC8 gene and activates the expression of the latter (Wysocka et al., 2006b). JMJD2A and $\mathrm{CHD}$, two other H3K4me-binding proteins, possess enzymatic activities themselves and can directly deliver enzymatic activities to chromatin when recruited (Huang et al., 2006;PrayGrant et al., 2005;Sims, III et al., 2005).

The link between histone modifications and transcriptional regulation has been widely studied. It has been found that a specific modification can be associated with transcriptional activation or repression. Among the histone modifications, methylation and acetylation of $\mathrm{H} 3$ and $\mathrm{H} 4$ play a major role in the regulation of transcriptional activity (Berger, 2007; Jenuwein and Allis, 2001;Li et al., 2007a;Shahbazian and Grunstein, 2007). Methylation, which occurs on 
either a lysine or an arginine residue, is catalyzed by three different classes of methyltransferases: SET domain-containing histone methyltransferases (HMTs), non-SET domain-containing lysine methyltransferases as well as protein arginine methyltransferase (PRMT). Methylation is implicated in both activation and repression of transcription depending on the methylation site and the type of methyltransferase involved (Shilatifard, 2006;Wysocka et al., 2006a). For example, methylation of lysine 4, 36 or 79 of $\mathrm{H} 3$ correlates with activation of transcription whereas methylation of lysine 9, 27 of $\mathrm{H} 3$ or lysine 20 of $\mathrm{H} 4$ is usually linked to transcriptional repression (Pawlak and Deckert, 2007). Type I PRMT, such as CARM1 (cofactor associated arginine methyltransferase 1), PRMT1 and PRMT2, catalyze the formation of monomethyland asymmetric dimethyl-arginine derivatives and is involved in transcriptional activation. Type II PRMT, such as PRMT5, catalyzes the formation of monomethyl- and symmetric dimethyl-arginine derivatives and is involved in transcriptional repression. In addition, a lysine can be mono-, di- or trimethylated with different effect on gene transcription (SantosRosa et al., 2002;Schneider et al., 2005). Both lysine and arginine methylations can be reversed by histone demethylases, which had been discovered many years after the discovery of HMTs. LSD1 was the first histone demethylase discovered in 2004 and was shown to demethylate H3K4 and to repress transcription (Shi et al., 2004). However, LSD1 was also shown to demethylate $\mathrm{H} 3 \mathrm{~K} 9$ and activate transcription when present in a complex with the androgen receptor (Metzger et al., 2005). Following the discovery of LSD1, a number of other related enzymes were subsequently discovered. Among them, Jumonji domain-containing 6 protein (JMJD6) is the only direct arginine demethylase reported to date shown to demethylate $\mathrm{H} 3$ at arginine 2 and $\mathrm{H} 4$ at arginine 3 (Chang et al., 2007). In addition, human peptidylarginine deiminase 4 protein $(\operatorname{Pad} 4)$ can regulate histone arginine methylation by converting monomethylated arginine into citrulline via demethylimination or deimination (Cuthbert et al., 2004; Wang et al., 2004). Histone methylation may affect the binding of other histone-modifying enzymes to the chromatin, which then mediates other posttranscriptional modifications, such as histone phosphorylation and DNA methylation (Mosammaparast and Shi, 2010;Pedersen and Helin, 2010).

Acetylation, another well-characterized modification, occurs on lysine residues mainly in the N-terminal tail of core histones. However, a lysine 56 within the globular domain of H3 (H3K56) has been found to be acetylated in yeast. Yeast protein SPT10, a putative histone acetyltransferase (HAT), was shown to mediate the H3K56 acetylation of histone genes at their promoter regions. H3K56 acetylation allows the recruitment of Snf5, an essential component of SWI/SNF chromatin remodeling complex and subsequently regulating transcription ( $\mathrm{Xu}$ et al., 2005). Compared with the SPT10, the Rtt109 acetyltransferase mediates H3K56 acetylation more globally (Driscoll et al., 2007;Han et al., 2007;Schneider et al., 2006). The acetylation level correlates with transcriptional activation (Davie, 2003;Legube and Trouche, 2003). The level of acetylation is balanced by HATs and HDACs. Generally, increased levels of histone acetylation by HATs enhance chromatin decondensation and DNA accessibility for transcription factors to activate gene expression. In contrast to acetylation, deacetylation of histones catalyzed by HDACs leads to chromatin condensation and gene silencing (Berger, 2007; Li et al., 2007a). The relationship between histone 
acetylation and gene expression has been well documented (Verdone et al., 2006). HATs can also acetylate non-histone proteins, such as transcription factors and nuclear receptors to facilitate gene expression (Bannister and Miska, 2000;Masumi, 2011)

Other histone modifications, such as phosphorylation, ubiquitylation and sumoylation, have also been shown to be involved in transcriptional regulation. For example, H3S10 phosphorylation has been demonstrated to be involved in the activation of NF- $\kappa B$-regulated genes as well as "immediate early" genes, such as c-fos and c-jun (Macdonald et al., 2005). Ubiquitination of H2AK119 and H2BK120 are associated with transcriptional repression and activation, respectively (Wang et al., 2006; Zhu et al., 2005).

\subsection{Chromatin remodelling complex and transcription}

The second major class of chromatin-modifying factors are the protein complexes that use energy from ATP hydrolysis to alter nucleosomal structure and DNA accessibility and hence are generally referred to as chromatin remodeling complex (Flaus and Owen-Hughes, 2004;Saha et al., 2006). Each ATP-dependent chromatin-remodeling complex characterized to date contains a highly conserved ATPase subunit that belongs to the SNF2 ATPase superfamily (Marfella CGA, Mutate Res, 2007). Based on the similarities of their ATPase subunits and the presence of other conserved domains, these complexes can be classified into at least four different families (Figure 2): the SWI/SNF (mating type switching /sucrose non-fermenting) family; the ISWI (imitation switch) family; the NuRD/Mi-2/CHD (chromodomain helicase DNA-binding) family and INO80 (inositol requiring 80) family (Farrants, 2008;Saha et al., 2006). The ATPase subunits of the SWI/SNF family members, including yeast Snf2 and Sth1, Drosophila melangaster brahma (BRM) and mammalian BRM and BRG1 (brahma-related gene 1), contain an C-terminal bromodomains which recognize and binds to acetylated histone tails (Hassan et al., 2002;Marfella and Imbalzano, 2007). The members of ISWI family, such as yeast homologues ISW1 and ISW2, and mammalian homologues SNF2H and SNF2L, each contains an ATPase subunit with homology to Drosophila ISWI protein and has nucleosome-stimulated ATPase activity. These enzymes are characterized by the presence of a SANT (SWI3-ADA2NCoR-TFIIIB) domain, which functions as a histone-tail-binding module (Boyer et al., 2004; de la Serna et al., 2006). SANT domain has been found in a number of transcriptional regulatory proteins and is therefore thought to play a role in transcriptional regulation (Aasland et al., 1996; Boyer et al., 2002). The NuRD/Mi-2/CHD family members include a number of proteins that are highly conserved from yeast to humans and are characterized by the presence of two $\mathrm{N}$-terminal chromodomains involved in the remodeling of chromatin structure and regulation of transcription (Brehm et al., 2004;Eissenberg, 2001;Jones et al., 2000). The INO80 family contains the INO80 remodeling complex (INO80.com) and the SWR1 remodeling complex (SWR1.com), which are distinguished by the split ATPase domains and the presence of two RuvB-like proteins, Rvb1 and Rvb2 (Bao and Shen, 2007).

ATP-dependent chromatin remodelers can reposition (slide, twist, or loop) nucleosomes along the DNA, evict histones from DNA or facilitate exchange of histone variants, and thus creating nucleosome-free regions for gene activation (Figure 3) (Wang et al., 2007). 


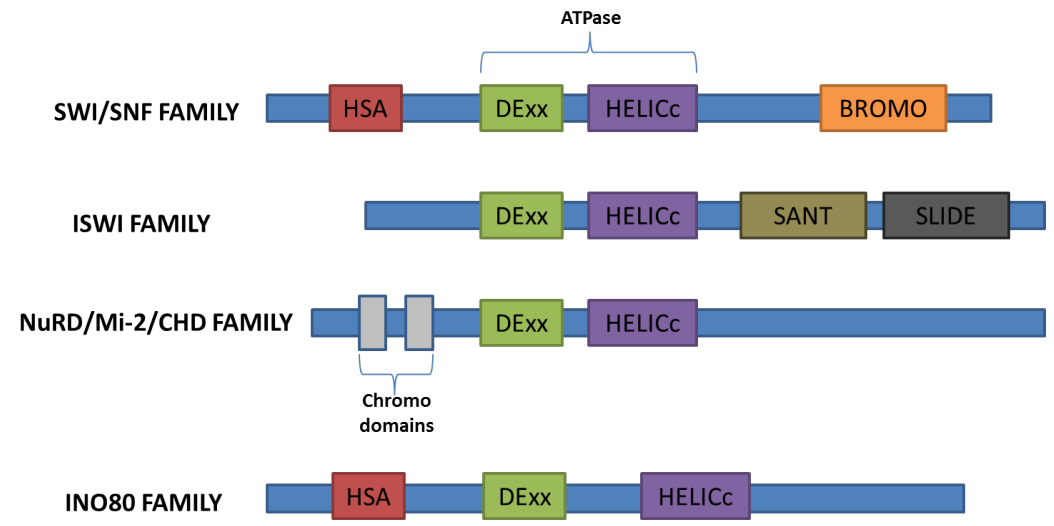

Figure 2. ATPase subunits of the four main families of ATP-dependent chromatin remodeling complexes. The ATPase subunit of each ATP-dependent chromatin-remodeling complex belongs to the SNF2 ATPase superfamily, whose ATPase domain comprises an N-terminal DExx and a C-terminal HELICc subdomain, separated by an insert region. The SWI/SNF family contains an HSA domain for actin binding, and a bromodomain which recognizes and binds to the acetylated histone tails. The ISWI family contains the SANT and SLIDE domains, important for histone binding. The CHD/NURD/Mi-2 family is characterized by the presence of two N-terminal chromodomains that is involved in the remodeling of chromatin structure and the transcriptional regulation of genes. The INO80 family, like the SWI/SNF family, also contains an HSA domain, however the insert region between the DExx and the HELICc subdomains is three times longer than that of other three families.

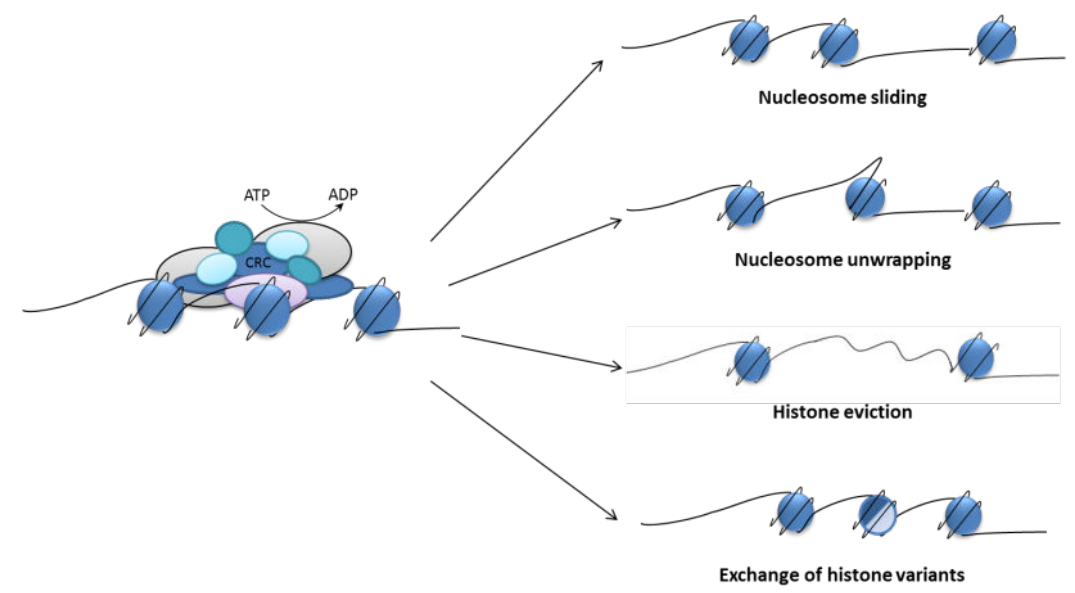

Figure 3. Mechanisms of ATP-dependent chromatin remodeling activity to alter the accessibility of nucleosomal DNA. Upon utilization of the energy from ATP hydrolysis, the nucleosomal structure is altered to make protected region of chromatin available to DNA binding protein complexes, such as transcription factors, which involves mobilization of nucleosome position(sliding), dissociation of DNA-histone contact (unwrapping), and eviction of histones (histone eviction). In some cases ATP dependent remodeling complexes can use the energy from ATP hydrolysis to introduce histone variants into the nucleosome (exchange of histone variants), such as $\mathrm{H} 2 \mathrm{~A}-\mathrm{H} 2 \mathrm{~B}$ or $\mathrm{H} 2 \mathrm{~A}$ variants (H2Avar)-H2B dimers. 


\section{The role of chromatin remodelling in the regulation of inflammatory gene expression}

The inflammatory response is a defense mechanism developed in higher organisms to protect themselves from infection with pathogens. It demands rapid and coordinated regulation of expression of multiple inflammatory genes in immune cells, including macrophages. It has increasingly become clear that alterations of chromatin architecture orchestrated by histone modifications and ATP-dependent chromatin remodeling complexes play a key role in controlling of inflammatory response genes (Medzhitov and Horng, 2009;Smale, 2010).

\subsection{LPS-induced chromatin modification and target gene expression}

LPS, a large molecule consisting of a lipid and a polysaccharide joined by a covalent bond, is the major component of the outer membrane of gram-negative bacteria and is one of the bestcharacterized agonist of host inflammatory response. LPS is recognized by Toll-like receptor 4 (TLR4) and activates the downstream signaling pathways, including the NF- $\mathrm{BB}$ signaling cascades, MAPK cascades and interferon regulatory factor (IRF) signaling cascades and induce the transcription of proinflammatory cytokine genes such as interleukin-6 (IL-6), IL-12 and tumor necrosis factor (TNF) (Akira and Takeda, 2004;Takeda et al., 2003). The first evidence of the involvement of chromatin remodeling in LPS-induced gene expression dates back to 1999, when it was observed that nucleosome remodeling appears to contribute to the rapid induction of p40 subunit of IL-12 (IL-12p40). Upon activation by LPS, a positioned nucleosome, which spans the IL-12p40 gene promoter, is rapidly and selectively repositioned prior to initiation of transcription process (Weinmann et al., 1999). Further studies demonstrated that the nucleosome remodeling by LPS requires TLR4 signaling but is independent of c-Rel, one of the NF$\mathrm{\kappa B}$ subunits required for transcription of integrated Il-12p40 promoter (Weinmann et al., 2001). In the year 2000, Saccani and colleagues (Saccani et al., 2002) revealed that upon LPS stimulation, H3 phosphorylation at serine 10 (H3S10) occurs selectively on the IL-12p40 promoter as well as promoters of a subset of other NF- $\kappa \mathrm{B}$-responsive proinflammatory genes such as IL-6, IL-8, and CC-chemokine ligand 2 (CCL2) but not TNF- $\alpha$, MIP- $1 \alpha$ and CCL3. This phosphorylation event was shown to be dependent on the activation of p38 MAPK signaling pathway by LPS, and specific inhibition of p38 activation blocks H3S10 phosphorylation, recruitment of NF- $\mathrm{kB}$ to the selective promoters and gene expression (Saccani et al., 2002). Therefore, it is postulated that phosphorylation of H3S10 via the p38 MAPK signaling pathway promotes the loosening of chromatin at certain selective promoters, thereby permitting accessibility to NF- $\kappa B$ and allowing transcription to occur. There are some evidence that link H3S10 mark with transcriptional activation. Serine to alanine substitution at position 10 of H3 or deletion of Snf1, a histone H3 kinase which phosphorylates the serine 10, abrogates transcriptional activation of LPS- inducible genes (Lo et al., 2001;Lo et al., 2000).

LPS activates TLR-dependent signaling to produce inflammatory cytokines and chemokines, which contribute to the efficient control and clearance of invading pathogens. However, production of these inflammatory mediators is tightly regulated because excessive production results in amplified inflammatory response and fatal illness characteristic of severe septic 
shock. Therefore, the host has readily available mechanisms in place which allow to dampen the response to LPS or even confer unresponsiveness to successive stimuli with LPS, a phenomenon named LPS or endotoxin tolerance (Cavaillon and Adib-Conquy, 2006;Cavaillon et al., 2003). The mechanisms underlying endotoxin tolerance are not completely understood, but are characterized by impaired TLR-mediated activation of both NF- $\kappa B$ - and MAPKdependent genes (Adib-Conquy et al., 2006;Adib-Conquy et al., 2000). Endotoxin tolerance has been shown to be associated with chromatin remodeling in the promoter regions of several tolerizable genes (Chan et al., 2005;El et al., 2007). Chang and colleagues have demonstrated that chromatin remodeling and NF- $\kappa B$ p 65 recruitment at the IL- $1 \beta$ gene promoter are altered in LPS-tolerant THP-1 cells, when compared to normal THP-1 cells (Chan et al., 2005). Upon LPS treatment, increased phosphorylation of H3S10 and demethylation of H3K9 are observed in normal THP-1 cells, which represent an "open" chromatin state; however, these modifications are impaired in LPS-tolerant cells. Concomitantly, recruitment of NF- $\kappa$ B p 65 but not NF$\kappa B$ p50 to the IL-1 gene promoter is impaired in LPS-tolerant cells despite that the activation and nuclear accumulation of NF- $\kappa \mathrm{B}$ is not changed. Similar histone modifications and NF- $\kappa \mathrm{B}$ binding were also observed at the TNF- $\alpha$ promoter during endotoxin tolerance (El et al., 2007). Interestingly, LPS tolerance negatively regulates expression of proinflammatory mediators without affecting antimicrobial effectors. Using microarrays and real-time PCR, Foster and colleagues (Foster et al., 2007) identified two classes of genes based on their responsiveness to re-stimulation with LPS: so called tolerizable genes, which include proinflammatory mediators, and non-tolerizable genes, which include antimicrobial effectors. Induction of tolerance to LPS inhibits expression of the proinflammatory genes, while the other group of genes remain inducible. Both classes of gene promoters show $\mathrm{H} 4$ acetylation and H3K4 tri-methylation, which mark an "open" chromatin state, upon initial stimulation with LPS; however, this kind of "open" chromatin state and recruitment of Brg1 are lost in tolerizable genes upon LPS restimulation. In contrast, these epigenetic marks are maintained in the genes that remain inducible. Aung and colleagues reported that HDACs are transiently repressed then induced to express in murine bone marrow-derived macrophages when treated with LPS. HDACs are recruited to different gene promoters to regulate the expression of the latter.

\subsection{Manipulation of host chromatin remodelling process by bacteria to facilitate infection}

Interestingly, intracellular pathogens, such as Listeria monocytogenes, Shigella flexneri, and Helicobacter pylori, affecting the expression of host defense gene via modulation of chromatin structure has also been reported in recent years. Listeria monocytogenes is a gram positive bacterium that causes listeriosis. Two different mechanisms have been reported to be used by L. monocytogenes to modify histones during the course of infection. In endothelial cells, $L$. monocytogenes has been shown to selectively induce serine 10 phosphorylation and lysine 14 acetylation of $\mathrm{H} 3$ and lysine 8 acetylation of $\mathrm{H} 4$ at the IL- 8 but not the Interferon- $\gamma$ (IFN- $\gamma$ ) gene promoter through the activation of $\mathrm{p} 38$ and ERK MAPK pathway. A subsequent study showed that activation of p38 MAPK signaling pathway and NF- $\kappa$ B by L. monocytogenes depends on nucleotide-binding oligomerization domain-containing protein 1 (NOD1). NOD1 is critical for L. monocytogenes induced secretion of IL-8. Interestingly, only invasive bacteria which can enter into the host cell cytoplasm induce IL-8 production in endothelial cells (Opitz 
et al., 2006). In another study, L. monocytogenes has been found to induce a dramatic H3 dephosphorylation at serine 10 (H3S10) as well as a deacetylation of $\mathrm{H} 4$ during early phase of infection (Hamon et al., 2007). In contrast to the report described as above, entry of bacteria into the host cells is not required for these histone modifications. The LLO released by $L$. monocytogenes is a member of CDC (cholesterol-dependent cytolysin) toxin family, which is identified as a major effector sufficient for induction of H3S10 dephosphorylation and H4 deacetylation. LLO-induced H3S10 dephosphorylation specifically occurs in the case of genes whose expression is regulated by LLO, a number of which are involved in immunity. Interestingly, other members of the large family of CDC toxins, such as PFO and PLY secreted by Clostridium perfringens and Streptococcus pneumonia, respectively, dephosphorylate H3S10 through a mechanism analogous to that of LLO (Hamon et al., 2007), suggesting that different bacteria may subvert immune response through a similar mechanism.

Shigella flexneri is a human intestinal pathogen, causing dysentery by invading the epithelium of the colon and is responsible, worldwide, for more than one million deaths per year. Arbibe and colleagues have shown that $S$. flexneri infection abrogates phosphorylation of H3S10 at the promoters of a specific subset of genes, such as IL-8 and CCL-20. The underlying mechanism is that the type III effector protein, OspF, secreted by $S$. flexneri enters into the nucleus and specifically dephosphorylates ERK and p38 MAPKs and then blocks MAPK-dependent phosphorylation of H3S10. This occurs in a gene-selective way, and renders selected gene promoter sites inaccessible to NF- $\kappa \mathrm{B}$, thereby reducing the expression of a subset of NF- $\kappa \mathrm{B}-$ responsive genes, including IL8 (Arbibe et al., 2007). This specificity might be a consequence of OspF's ability to inactivate MAPKs, thereby preventing them from entering into nucleus. Once activated, MAPKs translocate into nucleus and are recruited to the chromatin covering their target genes, where they regulate the phosphorylation of transcription factors, histones and chromatin-remodeling enzymes (Chow and Davis, 2006). It has been shown that OspFinduced down-regulation of inflammatory response is accomplished through the interaction of OspF with host retinoblastoma $(\mathrm{Rb})$ protein, which has been linked to histone modification (Zurawski et al., 2009). OspF also has the phosphothreonine lyase activity, a unique activity that has been found in a family of conserved effectors secreted by type III secretion system including OspF, SpvC from nontyphoid Salmonella species, and HopAI1 from the plant pathogen Pseudomonas syringae (Kramer et al., 2007;Li et al., 2007b;Zhang et al., 2007). These effectors specifically inactivate their host MAPK pathway by carrying out a $\beta$ elimination reaction to irreversibly remove the phosphate moiety from the phosphothreonine in phosphorylated MAPKs. Inhibition of MAPK signaling by OspF attenuates the recruitment of polymorphonuclear leukocytes to Shigella infection sites by suppressing the activation of a portion of NF-kB-responsive genes in mice (Arbibe et al., 2007), thereby contributing to the survival and persistent infection of the pathogens.

Helicobacter pylori is a Gram-negative bacterium that colonizes the human gastric mucosa. The chronic infection generates a state of inflammation which may develop toward chronic gastritis, peptic ulcers and gastric malignancies (Peek, Jr. and Crabtree, 2006). The virulence factors of Helicobacter pylori have been suggested to play a crucial role in the development of inflammation and in affecting the host immune system (Gebert et al., 2003;Lu et al., 2005). For example, in 
mouse macrophage, H. pylori peptidyl prolyl cis-, trans-isomerase (HP0175) has been shown to induce H3S10 phosphorylation at the IL-6 promoter resulting in increased IL-6 gene transcription and protein expression (Pathak et al., 2006). HP0175-induced IL-6 gene transcription is dependent on the TLR4 -dependent activation of ERK and p38 MAPKs, which subsequently activate mitogen- and stress-activated protein kinase 1 (MSK1), a serine kinase responsible for $\mathrm{H} 3 \mathrm{~S} 10$ phosphorylation. This modification allows for recruitment of NF- $\kappa \mathrm{B}$ to the IL- 6 promoter and activation of gene transactivation. Interestingly, H. pylori infection has also been shown to dephosphorylate H3S10 and deacetylate H3K23 in a time- and dose- dependent manner in gastric epithelial cells (Ding et al., 2010). Therefore, the effect of a specific histone modification in host cells appears to be cell type specific and gene promoter specific. Further studies demonstrate that cag pathogenicity island (PAI) is responsible for the dephosphorylation of $\mathrm{H} 3 \mathrm{~S} 10$ and this modification is independent of ERK and p38 signaling pathways as well as IFN signaling. In addition, H3S10 dephosphorylation is associated with changes in the host gene expression, which contributes to bacterial infection and pathogenesis (Ding et al., 2010). Treatment of gastric epithelial cells with TSA, a general inhibitor of HDACs which non-specifically increases histone $\mathrm{H} 3$ and $\mathrm{H} 4$ acetylation at multiple sites results in altered gene transcription pattern in both $I L-8$ and c-fos genes upon $H$. pylori infection. TSA reduces IL- 8 but increases c-fos gene transcription in the presence of H. pylori infection (Ding et al., 2010). H. pylori has also been shown to regulate the cell cycle controlled protein $\mathrm{p} 21(\mathrm{WAF})$, which is associated with the release of HDAC-1from the promoter and histone $\mathrm{H} 4$ acetylation (Xia et al., 2008).

\section{Chromatin remodeling and IFN- $\gamma$-induced transcriptional response}

IFN- $\gamma$ is a cytokine secreted by activated T cells and natural killer cells. IFN- $\gamma$ can induce expression of the major histocompatibility complex class II (MHC-II) on the cell surface (Boehm et al., 1997), which presents antigens to $\mathrm{CD}^{+} \mathrm{T}$ cells and plays a crucial role in normal immune response. IFN- $\gamma$ activates gene expression mainly via the activation of JAK (Janus tyrosine kinase)/STATI (signal transducer and activator of transcription) signaling pathway, leading to the translocation of active STAT1 homodimers into the nucleus. The STAT1 homodimers then bind to the IFN- $\gamma$-activated sites (GAS) present in the promoters of IFN- $\gamma$-responsive genes thereby mediating the transcription of these genes, including class II transactivator (CIITA), which is necessary for both constitutive and inducible expression of MHC-II (Schroder et al., 2004).

Chromatin remodeling, mediated by ATP-dependent chromatin remodeling complex and or histone-modifying enzymes, has also been shown to be involved in the activation of IFN$\gamma$-responsive genes, such as CIITA and HLA-DR (Ni et al., 2005;Pattenden et al., 2002;Zika et al., 2003). SWI/SNF complex often cooperates with histone-modifying enzymes to regulate transcription of genes, including those which are induced by IFN- $\gamma$ (Chi, 2004;Wright and Ting, 2006). Studies have demonstrated that the SWI/SNF complex and CREB-binding protein $(\mathrm{CBP})$, a transcriptional co-activator with histone acetyltransferase activity, are recruited to CIITA promoter in an IFN- $\gamma$-inducible fashion, leading to transcriptional 
activation of CIITA (Kretsovali et al., 1998;Pattenden et al., 2002). HLA-DR is a MHC-II surface molecule whose transcriptional activation is tightly associated with CIITA. However, forced expression of CIITA in BRG1- and BRM-deficient SW13 cells cannot activate expression of the MHC-II genes (Mudhasani and Fontes, 2002). BRG1 or BRM represent the catalytic subunit of mammalian SWI/SNF chromatin remodeling complex, suggesting that the SWI/SNF complex, which contains BRG1 might play additional roles in MHC-II expression. Further studies have indicated that BRG1 is recruited by CIITA to the MHCII gene promoters and this recruitment is essential for activation of MHC-II gene expression (Mudhasani and Fontes, 2002). Interestingly, CIITA itself has intrinsic HAT activity, which can bind not onlyBRG1 but also HATs, such as CBP and/or p300 (Ting and Trowsdale, 2002). Furthermore, CIITA is associated with increased acetylation modifications of $\mathrm{H} 3$ and $\mathrm{H} 4$ at MHC-II promoter mediated directly through its intrinsic HAT activity or by the recruitment of HATs, such as CBP (Beresford and Boss, 2001;Kretsovali et al., 1998). IFN- $\gamma$ induced transactivation of CIITA and expression of MHC-II is inhibited by HDACs/ mSin3A corepressor complex whereas enhanced by TSA, a general inhibitor of HDAC. Coimmunoprecipitation assay revealed that CIITA interacts strongly with HDAC1 and weakly with HDAC2 (Zika et al., 2003). All these data suggest that CIITA may act as a modulator to coordinate functions of chromatin remodeling complex, HATs and HDACs.

In the context of host-pathogen interaction, intracellular pathogens have been shown to subvert the host immune response by affecting the macrophage responsiveness to IFN- $\gamma$ but the underlying mechanism remains unclear. Intracellular pathogens may affect IFN- $\gamma$ response via different ways. For example, Leishamania donovani inhibited IFN- $\gamma$ response through down-regulation of IFN- $\gamma$ receptor expression or interfering with the JAK/STAT1 signaling pathway (Nandan and Reiner, 1995;Ray et al., 2000). By contrast, mycobacteria such as Mycobacterium avium and Mycobacterium tuberculosis impair IFN- $\gamma$ response through inhibition of IFN- $\gamma$-responsive gene expression without interfering with the JAK/STAT1 signaling pathway (Kincaid EZ, J Immunol, 2003, 171:2042-2049). Interestingly, only a subset of IFN- $\gamma$ responsive genes get affected, including CIITA, HLA-DR and CD64, while others remained unaffected (Pennini et al., 2006;Wang et al., 2005). Further studies showed that infection with $M$. tuberculosis affects the chromatin remodeling on CIITA gene since IFN- $\gamma$ -induced histone acetylation and recruitment of BRG1 were both impaired (Pennini et al., 2006). Additionally, LpqH, a mycobacterial cell wall protein, induces binding of the C/EBP transcriptional repressor to the CIITA promoter and inhibits IFN- $\gamma$-induced CIITA transcription (Pennini et al., 2007). It has been shown that C/EBP can recruit HDAC-1containing transcriptional repressor complex to the promoter of peroxisome proliferatoractivated receptor beta thereby inhibiting its transcription (Di-Poi et al., 2005). Therefore, $M$. tuberculosis might induce the recruitment of C/EBP resulting in transcriptional repression. The exact molecular mechanism by which $M$. tuberculosis inhibits IFN- $\gamma$-induced CIITA transcription remains to be elucidated. Similarly to CIITA, IFN- $\gamma$-induced histone acetylation gets impaired at the HLA-DR promoter and HLA-DR transcription becomes inhibited when the cells get infected with M. tuberculosis. Furthermore, inhibition of HDAC 
activities rescues histone acetylation, suggesting a role of HDACs in the transcriptional repression induced by M. tuberculosis (Wang et al., 2005). Indeed, Mycobacterial infection increases the expression of mSin3A (a co-repressor associated HDACs), enabling competition with CBP for binding to the HLA-DR promoter.

A recent study has demonstrated that infection with Toxoplasma gondii renders murine macrophages globally unresponsive to IFN- $\gamma$ stimulation without affecting the nuclear translocation of STAT1 triggered by IFN- $\gamma$ in infected macrophages. However, the binding of STAT1 to the STAT1-responsive promoters is aberrant. A number of genes, which were induced by IFN- $\gamma$ in uninfected macrophages, were not induced in the T. gondii-infected cells. Among them, there are several genes previously shown to be repressed by $T$. gondii, such as CIITA, MHC class II molecule H2-E $\alpha$, and interferon- regulatory factor 1(IRF-1) (Lang et al., 2012). By analyzing the underlying mechanism, the authors revealed that assembly of chromatin remodeling complex and histone acetylation at the IFN- $\gamma$-responsive promoters are impaired upon infection with $T$. gondii. Treatment with HADC inhibitor restores the responsiveness of T. gondii-infected macrophages to IFN- $\gamma$, leading to an increase in the expression of IFN- $\gamma$-inducible genes, such as CIITA and H2-A/E.

\section{The potential role of HDAC inhibitors in treatment of infection}

HDAC inhibitors have been developed clinically for cancer therapy due to their abilities to induce cell-cycle arrest and apoptosis (Adcock, 2007). Studies have demonstrated that HDAC inhibitors can exert anti-inflammatory effects via the suppression of cytokine and nitric oxide production (Blanchard and Chipoy, 2005;Dinarello et al., 2011), suggesting their therapeutic potential in inflammatory diseases including infectious diseases. For example, HDAC inhibitors have been examined for the treatment of HIV infection and the current results are exciting and encouraging (Wightman et al., 2012). Couple of other studies have demonstrated that HDAC inhibitors, TSA and apicidin, can inhibit the growth of Plasmodium falciparum, the main parasite causing malaria in humans (Colletti et al., 2001a;Colletti et al., 2001b). Similarly, azelaic bishydroxamic acid and suberohydroxamic acid, two other HDAC inhibitors, also show anti-malarial activity against P. falciparum (Andrews et al., 2000). The potential of HDAC inhibitors as anti-bacterial agents has also been investigated; however, the results are contradictory.

\subsection{Inhibition of infection by targeting histone modifying enzymes in the pathogen}

Candida albicans is an opportunistic pathogen that is normally found in the gut microflora of healthy individuals; however, C. albicans can cause severe and life-threatening diseases in immuosuppressed patients such as HIV infected, organ transplant and cancer chemotherapy patients (Tzung et al., 2001). There is a very high rate of mortality from systemic candidiasis, ranging between 14 and $90 \%$ and averaging between 30 to $40 \%$, depending on the disease group studied (Blot et al., 2003). For patients with Candida infections, antifungal drug resistance 
is a major clinical problem. H3K56 acetylation is mediated by HAT Rtt109 and seems to be much more abundant in yeasts than in mammals (Garcia et al., 2007a;Xie et al., 2009), and close homologues of Rtt109 have not yet been detected in mammals (Bazan, 2008). Therefore, it is expected that Rtt109 might be a unique target for antifungal therapeutics. Indeed, Wurtele and colleagues demonstrated that modulation of the acetylation of $\mathrm{H} 3 \mathrm{~K} 56$ exhibits potential as an anti-fungal therapy (Wurtele et al., 2010). Interestingly, similar results have been found in a study by Lopes da Rosa et al (Lopes da et al., 2010). Wurtele and colleagues showed that deleting Rtt109, an acetyltransferase of H3K56, leads to increased sensitivity to some anti-fungal drugs. Both teams also demonstrated that Rtt109 mutants are considerably less virulent in a mouse model infected with C.albicans. Wurtele and colleagues further investigated how the growth of $\mathrm{C}$. albicans is affected by chemical modification of $\mathrm{H} 3$ in vitro and in vivo. They have observed that the growth of $C$. albicans is greatly inhibited when HST3, the H3 deacetylase acting on lysine 56, is inhibited by nicotinamide (a form of Vitamin B3 and product of the NAD+dependent deacetylation reaction). Furthermore, modulation of $\mathrm{H} 3 \mathrm{~K} 56$ acetylation reduces the virulence of wild-type $C$. albicans in mice when nicotinamide was given in the drinking water of mice to repress HST3 (Wurtele et al., 2010). These results, together with the study by Lopes da Rosa and colleagues, provide basis for targeting H3 modifying enzymes to fight fungal infections. Although important catalytic residues in Rtt109 are much different from those in mammalian homologues, it is still a challenge to find suitable fungal-specific inhibitors of $\mathrm{H} 3$ modifying enzymes in the future.

\subsection{Effects of HDAC inhibitors on host defense against bacterial infection}

In a mouse model of septic shock induced by LPS, administration of of suberoylanilide hydroxamic acid (SAHA) (50mg/kg intraperitoneally), improves long-term survival rates of mice whether given before or post a lethal dose of LPS, which may be due to the downregulation of MyD88-dependent pathway and decreased expression of proinflammatory mediators such as TNF-alpha, IL-1 $\beta$, and IL-6 (Li et al., 2010;Li et al., 2009). Further studies demonstrated that treatment with SAHA increases anti-inflammatory IL-10 levels while decreasing proinflammatory IL-6 and MAP kinase production in the liver of septic shock mice (Finkelstein et al., 2010). In contrast, it has also been shown that treatment with HDAC inhibitors lead to impaired host defense against bacterial infections. Studies have shown that HDAC inhibitors, TSA, SAHA, and VPA, can impair innate immune responses to TLR agonists by down-regulating the expression of genes involved in microbial sensing, such as C-type lectins and adhesion molecules, as well as genes involved in host defense, such as cytokines and chemokines, thereby increasing susceptibility to infection (Roger et al., 2011). Interestingly, while LPS-induced IFN- $\beta$ production is enhanced by HDAC inhibitors, the expression of a number of IFN- $\beta$ /STAT1-dependent genes is strongly inhibited by TSA and VPA, suggesting that increased IFN- $\beta$ production cannot overcome the potent inhibitory effects of HDAC inhibitors. Surprisingly, VPA was shown to increase the mortality of mice infected with $C$. albicans or K. pneumonia, but protect mice from toxic shock and severe sepsis in mouse models (Roger et al., 2011). When murine macrophages were treated with TSA and VPA, their ability to kill Escherichia coli and Staphyloccocus aureus was attenuated, with impaired phagocytosis and production of reactive oxygen and nitrogen species (Mombelli et al., 2011). Together, these 
data reveal the complex effector mechanisms of HDAC inhibitors and suggest that more studies are required to fully understand this complex process.

\section{Concluding remarks}

The activation and suppression of innate immunity are central principles of host-pathogen interaction and need to be very well controlled. To establish persistent infection, intracellular pathogens must acquire efficient mechanisms to evade the host immune response. Interference with host posttranscriptional modifications by bacterial pathogens is a strategy widely used by the pathogens to promote survival and replication during the course of infection. MAPK, IFN- $\gamma$ and transcription factor NF- $\kappa B$ signaling pathways are common targets for bacteria-induced posttranscriptional modifications (Ribet and Cossart, 2010). Interestingly, in the past few years, evidence has accumulated that targeting of histone modifications and chromatin remodeling, and subsequently subverting the host immune response, is a new and exciting field in the study of host-pathogen interaction. Phosphorylation of $\mathrm{H} 3$ and acetylation of $\mathrm{H} 3$ and/or $\mathrm{H} 4$ at lysine residues are frequently associated with transactivation. Conversely, dephosphorylation and methylation of histones are more often associated with gene suppression (Berger, 2002;Kouzarides, 2007; Verdone et al., 2006). Several strains of bacteria, including L. monocytogenes, C. perfringens, S. pneumonia and $H$. pylori, induce the same dephosphorylation of H3S10, while S. flexneri blocks phosphorylation of H3S10; all of which lead to decreased phosphorylation of H3S10 and are associated with altered host immune response.

The molecular mechanisms by which bacterial infection induces histone modification and chromatin remodeling remain to be understood. For many pathogens, it is very difficult to hypothesize about the extent or the mechanics of epigenetic change they might induce. Currently available data largely provide snapshots of what is happening to the usual host genes studied in an infection model. More comprehensive global studies, such as ChIP-onchip (chromatin immunoprecipitation coupled with expression microarray technology) for mapping global chromatin modifications, are now necessary and possible. This might provide fundamental clues to better understand the role and mechanism of chromatin regulation in the control of immune gene expression in inflammatory and infectious diseases.

\section{Author details}

Yong Zhong Xu, Cynthia Kanagaratham and Danuta Radzioch

*Address all correspondence to: danuta.radzioch@mcgill.ca

Department of Medicine, McGill University, Montreal, Canada 


\section{References}

[1] Aasland, R, Stewart, A. F, \& Gibson, T. (1996). The SANT domain: a putative DNAbinding domain in the SWI-SNF and ADA complexes, the transcriptional co-repressor N-CoR and TFIIIB. Trends Biochem. Sci. 8788, 21

[2] Adcock, I. M. (2007). HDAC inhibitors as anti-inflammatory agents. Br. J. Pharmacol. 829831,150

[3] Adib-conquy, M, Adrie, C, Fitting, C, Gattolliat, O, Beyaert, R, \& Cavaillon, J. M. (2006). Up-regulation of MyD88s and SIGIRR, molecules inhibiting Toll-like receptor signaling, in monocytes from septic patients. Crit Care Med. 23772385, 34

[4] Adib-conquy, M, Adrie, C, Moine, P, Asehnoune, K, Fitting, C, Pinsky, M. R, Dhainaut, J. F, \& Cavaillon, J. M. (2000). NF-kappaB expression in mononuclear cells of patients with sepsis resembles that observed in lipopolysaccharide tolerance. Am. J. Respir. Crit Care Med. 18771883, 162

[5] Akira, S, \& Takeda, K. (2004). Toll-like receptor signalling. Nat. Rev. Immunol. 499511, 4

[6] Andrews, K. T, Walduck, A, Kelso, M. J, Fairlie, D. P, Saul, A, \& Parsons, P. G. (2000). Anti-malarial effect of histone deacetylation inhibitors and mammalian tumour cytodifferentiating agents. Int. J. Parasitol. 761768, 30

[7] Arbibe, L, Kim, D. W, Batsche, E, Pedron, T, Mateescu, B, Muchardt, C, Parsot, C, \& Sansonetti, P. J. (2007). An injected bacterial effector targets chromatin access for transcription factor NF-kappaB to alter transcription of host genes involved in immune responses. Nat. Immunol. 4756, 8

[8] Bannister, A. J, \& Miska, E. A. (2000). Regulation of gene expression by transcription factor acetylation. Cell Mol. Life Sci. 11841192, 57

[9] Bao, Y, \& Shen, X. (2007). INO80 subfamily of chromatin remodeling complexes. Mutat. Res. 1829, 618

[10] Bazan, J. F. (2008). An old HAT in human CBP and yeast Rtt109. Cell Cycle. 7, 1884-1886., 300.

[11] Beresford, G. W, \& Boss, J. M. (2001). CIITA coordinates multiple histone acetylation modifications at the HLA-DRA promoter. Nat. Immunol. 652657, 2

[12] Berger, S. L. (2002). Histone modifications in transcriptional regulation. Curr. Opin. Genet. Dev. 142148, 12

[13] Berger, S. L. (2007). The complex language of chromatin regulation during transcription. Nature. 407412, 447 
[14] Blanchard, F, \& Chipoy, C. (2005). Histone deacetylase inhibitors: new drugs for the treatment of inflammatory diseases? Drug Discov. Today. 197204, 10

[15] Blot, S. I, Hoste, E. A, Vandewoude, K. H, \& Colardyn, F. A. (2003). Estimates of attributable mortality of systemic candida infection in the ICU. J. Crit Care. 130131, 18

[16] Boehm, U, Klamp, T, Groot, M, \& Howard, J. C. (1997). Cellular responses to interferon-gamma. Annu. Rev. Immunol. 74995, 15

[17] Boyer, L. A, Langer, M. R, Crowley, K. A, Tan, S, Denu, J. M, \& Peterson, C. L. (2002). Essential role for the SANT domain in the functioning of multiple chromatin remodeling enzymes. Mol. Cell. 935942, 10

[18] Boyer, L. A, Latek, R. R, \& Peterson, C. L. (2004). The SANT domain: a unique histone-tail-binding module? Nat. Rev. Mol. Cell Biol. 158163, 5

[19] Brehm, A, Tufteland, K. R, Aasland, R, \& Becker, P. B. (2004). The many colours of chromodomains. Bioessays. 133140, 26

[20] Cavaillon, J. M, \& Adib-conquy, M. (2006). Bench-to-bedside review: endotoxin tolerance as a model of leukocyte reprogramming in sepsis. Crit Care. 10, 233.

[21] Cavaillon, J. M, Adrie, C, Fitting, C, \& Adib-conquy, M. (2003). Endotoxin tolerance: is there a clinical relevance? J. Endotoxin. Res. 101107, 9

[22] Chan, C, Li, L, Mccall, C. E, \& Yoza, B. K. (2005). Endotoxin tolerance disrupts chromatin remodeling and NF-kappaB transactivation at the IL-1beta promoter. J. Immunol. 461468,175

[23] Chang, B, Chen, Y, Zhao, Y, \& Bruick, R. K. (2007). JMJD6 is a histone arginine demethylase. Science. \% 19;318444447

[24] Chi, T. view of the immune system. Nat. Rev. Immunol. 965977, 4

[25] Chow, C. W, \& Davis, R. J. (2006). Proteins kinases: chromatin-associated enzymes? Cell. 887890, 127

[26] Clapier, C. R, \& Cairns, B. R. (2009). The biology of chromatin remodeling complexes. Annu. Rev. Biochem. 273304doi:annurev.biochem.77.062706.153223., 273-304., 78

[27] Colletti, S. L. (2001a). Broad spectrum antiprotozoal agents that inhibit histone deacetylase: structure-activity relationships of apicidin. Part 1. Bioorg. Med. Chem. Lett. 107111, 11

[28] Colletti, S. L. (2001b). Broad spectrum antiprotozoal agents that inhibit histone deacetylase: structure-activity relationships of apicidin. Part 2. Bioorg. Med. Chem. Lett. 113117, 11

[29] Cuthbert, G. L. (2004). Histone deimination antagonizes arginine methylation. Cell. 545553,118 
[30] Davie, J. R. (2003). Inhibition of histone deacetylase activity by butyrate. J. Nutr. 133, 2485S-2493S.

[31] De La Serna, I. L, Ohkawa, Y, \& Imbalzano, A. N. (2006). Chromatin remodelling in mammalian differentiation: lessons from ATP-dependent remodellers. Nat. Rev. Genet. 461473, 7

[32] Di-poi, N, Desvergne, B, Michalik, L, \& Wahli, W. (2005). Transcriptional repression of peroxisome proliferator-activated receptor beta/delta in murine keratinocytes by CCAAT/enhancer-binding proteins. J. Biol. Chem. 3870038710, 280

[33] Dinarello, C. A, Fossati, G, \& Mascagni, P. (2011). Histone deacetylase inhibitors for treating a spectrum of diseases not related to cancer. Mol. Med. 333352, 17

[34] Ding, S. Z. (2010). Helicobacter pylori-induced histone modification, associated gene expression in gastric epithelial cells, and its implication in pathogenesis. PLoS. One. 5, e9875.

[35] Driscoll, R, Hudson, A, \& Jackson, S. P. (2007). Yeast Rtt109 promotes genome stability by acetylating histone $\mathrm{H} 3$ on lysine 56 . Science. 649652,315

[36] Eissenberg, J. C. (2001). Molecular biology of the chromo domain: an ancient chromatin module comes of age. Gene. 1929, 275

[37] El,Yoza, G. M, Hu, B. K, Cousart, J. Y, \& Mccall, S. L. C.E. ((2007). Epigenetic silencing of tumor necrosis factor alpha during endotoxin tolerance. J. Biol. Chem. 2685726864,282

[38] Farrants, A. K. (2008). Chromatin remodelling and actin organisation. FEBS Lett. 20412050,582

[39] Finkelstein, R. A, Li, Y, Liu, B, Shuja, F, Fukudome, E, Velmahos, G. C, Demoya, M, \& Alam, H. B. (2010). Treatment with histone deacetylase inhibitor attenuates MAP kinase mediated liver injury in a lethal model of septic shock. J. Surg. Res. 146154, 163

[40] Flaus, A, \& Owen-hughes, T. (2004). Mechanisms for ATP-dependent chromatin remodelling: farewell to the tuna-can octamer? Curr. Opin. Genet. Dev. 165173, 14

[41] Foster, S. L, Hargreaves, D. C, \& Medzhitov, R. (2007). Gene-specific control of inflammation by TLR-induced chromatin modifications. Nature. 972978, 447

[42] Galan, J. E, \& Cossart, P. (2005). Host-pathogen interactions: a diversity of themes, a variety of molecular machines. Curr. Opin. Microbiol. 13, 8

[43] Garcia, B. A. (2007a). Organismal differences in post-translational modifications in histones H3 and H4. J. Biol. Chem. 76417655, 282 
[44] Garcia, B. A, Shabanowitz, J, \& Hunt, D. F. (2007b). Characterization of histones and their post-translational modifications by mass spectrometry. Curr. Opin. Chem. Biol. 6673,11

[45] Gebert, B, Fischer, W, Weiss, E, Hoffmann, R, \& Haas, R. (2003). Helicobacter pylori vacuolating cytotoxin inhibits T lymphocyte activation. Science. 10991102, 301

[46] Glaser, K. B, Li, J, Staver, M. J, Wei, R. Q, Albert, D. H, \& Davidsen, S. K. (2003a). Role of class I and class II histone deacetylases in carcinoma cells using siRNA. Biochem. Biophys. Res. Commun. 529536, 310

[47] Glaser, K. B, Staver, M. J, Waring, J. F, Stender, J, Ulrich, R. G, \& Davidsen, S. K. (2003b). Gene expression profiling of multiple histone deacetylase (HDAC) inhibitors: defining a common gene set produced by HDAC inhibition in T24 and MDA carcinoma cell lines. Mol. Cancer Ther. 151163, 2

[48] Hamon, M. A, Batsche, E, Regnault, B, Tham, T. N, Seveau, S, Muchardt, C, \& Cossart, P. (2007). Histone modifications induced by a family of bacterial toxins. Proc. Natl. Acad. Sci. U. S. A. 1346713472, 104

[49] Hamon, M. A, \& Cossart, P. (2008). Histone modifications and chromatin remodeling during bacterial infections. Cell Host. Microbe. 100109, 4

[50] Han, J, Zhou, H, Horazdovsky, B, Zhang, K, Xu, R. M, \& Zhang, Z. (2007). Rtt109 acetylates histone $\mathrm{H} 3$ lysine 56 and functions in DNA replication. Science. 653655, 315

[51] Hassan, A. H, Prochasson, P, Neely, K. E, Galasinski, S. C, Chandy, M, Carrozza, M. J, \& Workman, J. L. (2002). Function and selectivity of bromodomains in anchoring chromatin-modifying complexes to promoter nucleosomes. Cell. 369379, 111

[52] Huang, Y, Fang, J, Bedford, M. T, Zhang, Y, \& Xu, R. M. (2006). Recognition of histone H3 lysine- 4 methylation by the double tudor domain of JMJD2A. Science. 748751,312

[53] Jenuwein, T, \& Allis, C. D. (2001a). Translating the histone code. Science. 10741080, 293

[54] Jones, D. O, Cowell, I. G, \& Singh, P. B. (2000). Mammalian chromodomain proteins: their role in genome organisation and expression. Bioessays. 124137, 22

[55] Kallin, E, \& Zhang, Y. (2004). Chromatin Remodelling. In: Encyclopedia of Biological Chemistry. , 456-463.

[56] Kouzarides, T. (2007). Chromatin modifications and their function. Cell. 693705, 128

[57] Kramer, R. W, Slagowski, N. L, Eze, N. A, Giddings, K. S, Morrison, M. F, Siggers, K. A, Starnbach, M. N, \& Lesser, C. F. (2007). Yeast functional genomic screens lead to identification of a role for a bacterial effector in innate immunity regulation. PLoS. Pathog. 3, e21. 
[58] Kretsovali, A, Agalioti, T, Spilianakis, C, Tzortzakaki, E, Merika, M, \& Papamatheakis, J. (1998). Involvement of CREB binding protein in expression of major histocompatibility complex class II genes via interaction with the class II transactivator. Mol. Cell Biol. 67776783, 18

[59] Lang, C, Hildebrandt, A, Brand, F, Opitz, L, Dihazi, H, \& Luder, C. G. (2012). Impaired chromatin remodelling at STATregulated promoters leads to global unresponsiveness of Toxoplasma gondii-Infected macrophages to IFN-gamma. PLoS. Pathog. 8, e1002483., 1 .

[60] Lee, H. S, Park, M. H, Yang, S. J, Jung, H. Y, Byun, S. S, Lee, D. S, Yoo, H. S, Yeom, Y. I, \& Seo, S. B. (2004). Gene expression analysis in human gastric cancer cell line treated with trichostatin A and S-adenosyl-L-homocysteine using cDNA microarray. Biol. Pharm. Bull. 14971503, 27

[61] Legube, G, \& Trouche, D. (2003). Regulating histone acetyltransferases and deacetylases. EMBO Rep. 944947, 4

[62] Li, B, Carey, M, \& Workman, J. L. (2007a). The role of chromatin during transcription. Cell. 707719, 128

[63] Li, H, Xu, H, Zhou, Y, Zhang, J, Long, C, Li, S, Chen, S, Zhou, J. M, \& Shao, F. (2007b). The phosphothreonine lyase activity of a bacterial type III effector family. Science. 10001003, 315

[64] Li, Y. (2010). Surviving lethal septic shock without fluid resuscitation in a rodent model. Surgery. 246254, 148

[65] Li, Y. (2009). Protective effect of suberoylanilide hydroxamic acid against LPS-induced septic shock in rodents. Shock. 517523, 32

[66] Lo, W. S, Duggan, L, Emre, N. C, Belotserkovskya, R, Lane, W. S, Shiekhattar, R, \& Berger, S. L. (2001). Snf1--a histone kinase that works in concert with the histone acetyltransferase Gcn5 to regulate transcription. Science. 11421146, 293

[67] Lo, W. S, Trievel, R. C, Rojas, J. R, Duggan, L, Hsu, J. Y, Allis, C. D, Marmorstein, R, \& Berger, S. L. (2000). Phosphorylation of serine 10 in histone H3 is functionally linked in vitro and in vivo to Gcn5-mediated acetylation at lysine 14. Mol. Cell. 917926, 5

[68] Lopes daR.J., Boyartchuk,V.L., Zhu,L.J., and Kaufman,P.D. ((2010). Histone acetyltransferase Rtt109 is required for Candida albicans pathogenesis. Proc. Natl. Acad. Sci. U. S. A. 15941599, 107

[69] Lu, H, Yamaoka, Y, \& Graham, D. Y. (2005). Helicobacter pylori virulence factors: facts and fantasies. Curr. Opin. Gastroenterol. 653659, 21

[70] Lusser, A, \& Kadonaga, J. T. (2003). Chromatin remodeling by ATP-dependent molecular machines. Bioessays. 11921200, 25 
[71] Macdonald, N. (2005). Molecular basis for the recognition of phosphorylated and phosphoacetylated histone h3 by 14-3-3. Mol. Cell. 199211, 20

[72] Marfella, C. G, \& Imbalzano, A. N. (2007). The Chd family of chromatin remodelers. Mutat. Res. 3040, 618

[73] Martin, C, \& Zhang, Y. (2005). The diverse functions of histone lysine methylation. Nat. Rev. Mol. Cell Biol. 838849, 6

[74] Martin, C, \& Zhang, Y. (2007). Mechanisms of epigenetic inheritance. Curr. Opin. Cell Biol. 266272, 19

[75] Masumi, A. (2011). Histone acetyltransferases as regulators of nonhistone proteins: the role of interferon regulatory factor acetylation on gene transcription. J. Biomed. Biotechnol. 2011:640610. doi:Epub;\% 2010 Dec 29., 640610.

[76] Medzhitov, R, \& Horng, T. (2009). Transcriptional control of the inflammatory response. Nat. Rev. Immunol. 692703, 9

[77] Mersfelder, E. L, \& Parthun, M. R. (2006). The tale beyond the tail: histone core domain modifications and the regulation of chromatin structure. Nucleic Acids Res. \% $19 ; 3426532662$

[78] Metzger, E, Wissmann, M, Yin, N, Muller, J. M, Schneider, R, Peters, A. H, Gunther, T, Buettner, R, \& Schule, R. (2005). LSD1 demethylates repressive histone marks to promote androgen-receptor-dependent transcription. Nature. 436439, 437

[79] Mombelli, M, Lugrin, J, Rubino, I, Chanson, A. L, Giddey, M, Calandra, T, \& Roger, T. (2011). Histone deacetylase inhibitors impair antibacterial defenses of macrophages. J. Infect. Dis. 13671374, 204

[80] Mosammaparast, N, \& Shi, Y. (2010). Reversal of histone methylation: biochemical and molecular mechanisms of histone demethylases. Annu. Rev. Biochem. 15579doi:annurev.biochem.78.070907.103946., 155-179., 79

[81] Mudhasani, R, \& Fontes, J. D. (2002). The class II transactivator requires brahma-related gene 1 to activate transcription of major histocompatibility complex class II genes. Mol. Cell Biol. 50195026, 22

[82] Nandan, D, \& Reiner, N. E. (1995). Attenuation of gamma interferon-induced tyrosine phosphorylation in mononuclear phagocytes infected with Leishmania donovani: selective inhibition of signaling through Janus kinases and Stat1. Infect. Immun. 44954500, 63

[83] Ni, Z, Karaskov, E, Yu, T, Callaghan, S. M, Park, S, Xu, D. S, Pattenden, Z, \& Bremner, S. G. R. ((2005). Apical role for BRG1 in cytokine-induced promoter assembly. Proc. Natl. Acad. Sci. U. S. A. 1461114616, 102

[84] Opitz, B, Puschel, A, Beermann, W, Hocke, A. C, Forster, S, Schmeck, B, Chakraborty, L. , V, Suttorp, T, \& Hippenstiel, N. S. ((2006). Listeria monocytogenes activated 
MAPK and induced IL-8 secretion in a nucleotide-binding oligomerization domain 1dependent manner in endothelial cells. J. Immunol. 176, 484-490., 38.

[85] Pathak, S. K, Basu, S, Bhattacharyya, A, Pathak, S, Banerjee, A, Basu, J, \& Kundu, M. $B$ activation and mitogen- and stress-activated protein kinase 1-triggered phosphorylation events are central to Helicobacter pylori peptidyl prolyl cis-, trans-isomerase (HP0175)-mediated induction of IL-6 release from macrophages. J. Immunol. 79507958,177

[86] Pattenden, S. G, Klose, R, Karaskov, E, \& Bremner, R. (2002). Interferon-gamma-induced chromatin remodeling at the CIITA locus is BRG1 dependent. EMBO J. 19781986, 21

[87] Pawlak, S, \& Deckert, J. (2007). Histone modifications under environmental stress. BIOLOGICAL LETT. 6573, 44

[88] Pedersen, M. T, \& Helin, K. (2010). Histone demethylases in development and disease. Trends Cell Biol. 662671, 20

[89] Peek, R. M. Jr. and Crabtree,J.E. ((2006). Helicobacter infection and gastric neoplasia. J. Pathol. 233248, 208

[90] Pena, P. V, Davrazou, F, Shi, X, Walter, K. L, Verkhusha, V. V, Gozani, O, Zhao, R, \& Kutateladze, T. G. (2006). Molecular mechanism of histone H3K4me3 recognition by plant homeodomain of ING2. Nature. 100103, 442

[91] Pennini, M. E, Liu, Y, Yang, J, Croniger, C. M, Boom, W. H, \& Harding, C. V. (2007). CCAAT/enhancer-binding protein beta and delta binding to CIITA promoters is associated with the inhibition of CIITA expression in response to Mycobacterium tuberculosis 19-kDa lipoprotein. J. Immunol. 69106918, 179

[92] Pennini, M. E, Pai, R. K, Schultz, D. C, Boom, W. H, \& Harding, C. V. (2006). Mycobacterium tuberculosis $19-\mathrm{kDa}$ lipoprotein inhibits IFN-gamma-induced chromatin remodeling of MHC2TA by TLR2 and MAPK signaling. J. Immunol. 43234330, 176

[93] Pray-grant, M. G, Daniel, J. A, Schieltz, D, \& Yates, J. R. III, and Grant,P.A. ((2005). Chd1 chromodomain links histone H3 methylation with SAGA- and SLIK-dependent acetylation. Nature. 434438,433

[94] Punga, T, \& Akusjarvi, G. (2000). The adenovirus-2 E1B-55K protein interacts with a $\mathrm{mSin3A}$ /histone deacetylase 1 complex. FEBS Lett. 248252, 476

[95] Radkov, S. A, Touitou, R, Brehm, A, Rowe, M, West, M, Kouzarides, T, \& Allday, M. J. (1999). Epstein-Barr virus nuclear antigen 3C interacts with histone deacetylase to repress transcription. J. Virol. 56885697, 73

[96] Ray, M, Gam, A. A, Boykins, R. A, \& Kenney, R. T. (2000). Inhibition of interferongamma signaling by Leishmania donovani. J. Infect. Dis. 11211128, 181 
[97] Ribet, D, \& Cossart, P. (2010). Post-translational modifications in host cells during bacterial infection. FEBS Lett. 27482758, 584

[98] Roberts, C. W, \& Orkin, S. H. (2004). The SWI/SNF complex--chromatin and cancer. Nat. Rev. Cancer. 133142, 4

[99] Roger, T. (2011). Histone deacetylase inhibitors impair innate immune responses to Toll-like receptor agonists and to infection. Blood. 12051217, 117

[100] Ruthenburg, A. J, Li, H, Patel, D. J, \& Allis, C. D. (2007). Multivalent engagement of chromatin modifications by linked binding modules. Nat. Rev. Mol. Cell Biol. 983994, 8

[101] Saccani, S, Pantano, S, \& Natoli, G. (2002). marking of inflammatory genes for increased NF-kappa B recruitment. Nat. Immunol. 3, 69-75., 38.

[102] Saha, A, Wittmeyer, J, \& Cairns, B. R. (2006). Chromatin remodelling: the industrial revolution of DNA around histones. Nat. Rev. Mol. Cell Biol. 437447, 7

[103] Sakabe, K, Wang, Z, \& Hart, G. W. (2010). Beta-N-acetylglucosamine (O-GlcNAc) is part of the histone code. Proc. Natl. Acad. Sci. U. S. A. 1991519920, 107

[104] Santos-rosa, H, Schneider, R, Bannister, A. J, Sherriff, J, Bernstein, B. E, Emre, N. C, Schreiber, S. L, Mellor, J, \& Kouzarides, T. (2002). Active genes are tri-methylated at K4 of histone H3. Nature. 407411, 419

[105] Schneider, J, Bajwa, P, Johnson, F. C, Bhaumik, S. R, \& Shilatifard, A. (2006). Rtt109 is required for proper H3K56 acetylation: a chromatin mark associated with the elongating RNA polymerase II. J. Biol. Chem. 3727037274, 281

[106] Schneider, J, Wood, A, Lee, J. S, Schuster, R, Dueker, J, Maguire, C, Swanson, S. K, Florens, L, Washburn, M. P, \& Shilatifard, A. (2005). Molecular regulation of histone H3 trimethylation by COMPASS and the regulation of gene expression. Mol. Cell. 849856,19

[107] Schroder, K, Hertzog, P. J, Ravasi, T, \& Hume, D. A. (2004). Interferon-gamma: an overview of signals, mechanisms and functions. J. Leukoc. Biol. 163189, 75

[108] Shahbazian, M. D, \& Grunstein, M. (2007). Functions of site-specific histone acetylation and deacetylation. Annu. Rev. Biochem. 75100, 76

[109] Shi, X. (2006). ING2 PHD domain links histone H3 lysine 4 methylation to active gene repression. Nature. 9699, 442

[110] Shi, Y, Lan, F, Matson, C, Mulligan, P, Whetstine, J. R, Cole, P. A, Casero, R. A, \& Shi, Y. (2004). Histone demethylation mediated by the nuclear amine oxidase homolog LSD1. Cell. 941953, 119

[111] Shi, Y, \& Whetstine, J. R. (2007). Dynamic regulation of histone lysine methylation by demethylases. Mol. Cell. 114, 25 
[112] Shilatifard, A. (2006). Chromatin modifications by methylation and ubiquitination: implications in the regulation of gene expression. Annu. Rev. Biochem. 24369, 75

[113] Shogren-knaak, M, Ishii, H, Sun, J. M, Pazin, M. J, Davie, J. R, \& Peterson, C. L. K16 acetylation controls chromatin structure and protein interactions. Science. 844847, 311

[114] Shogren-knaak, M, \& Peterson, C. L. (2006). Switching on chromatin: mechanistic role of histone H4-K16 acetylation. Cell Cycle. 13611365, 5

[115] Sims, R. J. III, Chen,C.F., Santos-Rosa,H., Kouzarides,T., Patel,S.S., and Reinberg,D. ((2005). Human but not yeast CHD1 binds directly and selectively to histone H3 methylated at lysine 4 via its tandem chromodomains. J. Biol. Chem. 4178941792, 280

[116] Smale, S. T. (2010). Selective transcription in response to an inflammatory stimulus. Cell. \% 19;140833844

[117] Strahl, B. D, \& Allis, C. D. (2000). The language of covalent histone modifications. Nature. 4145,403

[118] Takeda, K, Kaisho, T, \& Akira, S. (2003). Toll-like receptors. Annu. Rev. Immunol. 33576Epub;\% 2001 Dec;\% 19., 335-376., 21

[119] Tan, M. (2011). Identification of 67 histone marks and histone lysine crotonylation as a new type of histone modification. Cell. 10161028, 146

[120] Ting, J. P, \& Trowsdale, J. (2002). Genetic control of MHC class II expression. Cell. 109 Suppl:S2133S21-S33.

[121] Tzung, K. W. (2001). Genomic evidence for a complete sexual cycle in Candida albicans. Proc. Natl. Acad. Sci. U. S. A. 32493253, 98

[122] Valls, E, Blanco-garcia, N, Aquizu, N, Piedra, D, Estaras, C, \& Martinez-balbas, 1. C. , X. M.A. ((2007). Involvement of chromatin and histone deacetylation in SV40 T antigen transcription regulation. Nucleic Acids Res. 19581968, 35

[123] Verdone, L, Agricola, E, Caserta, M, \& Di, M. E. (2006a). Histone acetylation in gene regulation. Brief. Funct. Genomic. Proteomic. 209221, 5

[124] Wang, G. G, Allis, C. D, \& Chi, P. (2007). Chromatin remodeling and cancer, Part II: ATP-dependent chromatin remodeling. Trends Mol. Med. 373380, 13

[125] Wang, H, Zhai, L, Xu, J, Joo, H. Y, Jackson, S, Erdjument-bromage, H, Tempst, P, Xiong, Y, \& Zhang, Y. and H4 ubiquitylation by the CUL4-DDB-ROC1 ubiquitin ligase facilitates cellular response to DNA damage. Mol. Cell. 383394, 22

[126] Wang, Y, Curry, H. M, Zwilling, B. S, \& Lafuse, W. P. (2005). Mycobacteria inhibition of IFN-gamma induced HLA-DR gene expression by up-regulating histone deacetylation at the promoter region in human THP-1 monocytic cells. J. Immunol. 56875694, 174 
[127] Wang, Y. (2004). Human PAD4 regulates histone arginine methylation levels via demethylimination. Science. 279283, 306

[128] Weinmann, A. S, Mitchell, D. M, Sanjabi, S, Bradley, M. N, Hoffmann, A, Liou, H. C, \& Smale, S. T. (2001). Nucleosome remodeling at the IL-12 promoter is a TLR-dependent, Rel-independent event. Nat. Immunol. 2, 51-57., 40.

[129] Weinmann, A. S, Plevy, S. E, \& Smale, S. T. (1999). Rapid and selective remodeling of a positioned nucleosome during the induction of IL-12 transcription. Immunity. 11, 665-675., 40.

[130] Wightman, F, Ellenberg, P, Churchill, M, \& Lewin, S. R. (2012). HDAC inhibitors in HIV. Immunol. Cell Biol. 4754, 90

[131] Wright, K. L, \& Ting, J. P. (2006). Epigenetic regulation of MHC-II and CIITA genes. Trends Immunol. 405412, 27

[132] Wurtele, H, Tsao, S, Lepine, G, Mullick, A, Tremblay, J, Drogaris, P, Lee, E. H, Thibault, P, Verreault, A, \& Raymond, M. (2010). Modulation of histone H3 lysine 56 acetylation as an antifungal therapeutic strategy. Nat. Med. 774780, 16

[133] Wysocka, J, Allis, C. D, \& Coonrod, S. (2006a). Histone arginine methylation and its dynamic regulation. Front Biosci. 34455, 11

[134] Wysocka, J, Swigut, T, Milne, T. A, Dou, Y, Zhang, X, Burlingame, A. L, Roeder, R. G, Brivanlou, A. H, \& Allis, C. D. (2005). WDR5 associates with histone H3 methylated at $\mathrm{K} 4$ and is essential for H3 K4 methylation and vertebrate development. Cell. 859872,121

[135] Wysocka, J. (2006b). A PHD finger of NURF couples histone H3 lysine 4 trimethylation with chromatin remodelling. Nature. 8690, 442

[136] Xia, G, Schneider-stock, R, Diestel, A, Habold, C, Krueger, S, Roessner, A, Naumann, M, \& Lendeckel, U. (2008). Helicobacter pylori regulates WAF1) by histone H4 acetylation. Biochem. Biophys. Res. Commun. 369, 526-531., 21.

[137] Xie, W. (2009). Histone h3 lysine 56 acetylation is linked to the core transcriptional network in human embryonic stem cells. Mol. Cell. 417427, 33

[138] Xu, F, Zhang, K, \& Grunstein, M. (2005). Acetylation in histone H3 globular domain regulates gene expression in yeast. Cell. 375385, 121

[139] Zeng, L, \& Zhou, M. M. (2002). Bromodomain: an acetyl-lysine binding domain. FEBS Lett. \% 20;513124128

[140] Zhang, J. (2007). A Pseudomonas syringae effector inactivates MAPKs to suppress PAMP-induced immunity in plants. Cell Host. Microbe. 175185, 1 
[141] Zhu, B, Zheng, Y, Pham, A. D, Mandal, S. S, Erdjument-bromage, H, Tempst, P, \& Reinberg, D. (2005). Monoubiquitination of human histone H2B: the factors involved and their roles in HOX gene regulation. Mol. Cell. 601611, 20

[142] Zika, E, Greer, S. F, Zhu, X. S, \& Ting, J. P. (2003). Histone deacetylase 1/mSin3A disrupts gamma interferon-induced CIITA function and major histocompatibility complex class II enhanceosome formation. Mol. Cell Biol. 30913102, 23

[143] Zupkovitz, G. (2006). Negative and positive regulation of gene expression by mouse histone deacetylase 1. Mol. Cell Biol. 79137928, 26

[144] Zurawski, D. V, Mumy, K. L, Faherty, C. S, Mccormick, B. A, \& Maurelli, A. T. (2009). Shigella flexneri type III secretion system effectors OspB and OspF target the nucleus to downregulate the host inflammatory response via interactions with retinoblastoma protein. Mol. Microbiol. 350368, 71 